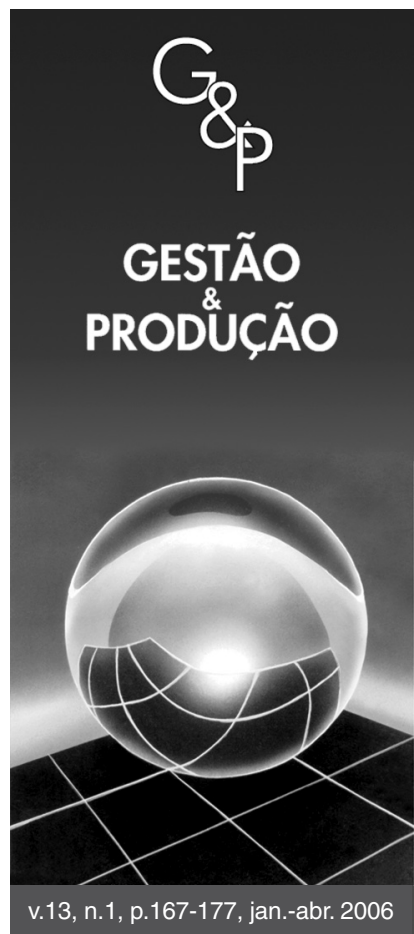

\title{
A ESTRUTURAÇÃO DA REDE DE EMPRESAS PROCESSADORAS DE AVES NO ESTADO DE SANTA CATARINA: GOVERNANÇA CONTRATUAL E DEPENDÊNCIA DE RECURSOS ${ }^{1}$
}

\author{
Raquel Nakazato Pinotti \\ Secretaria da Agricultura de SP/APTA Regional/PRDTA \\ Centro-Oeste/UPD-Bauru, Av. Rodrigues Alves, 40-40, CEP 17030-000, \\ Bauru, SP, Brasil, \\ e-mail: raquelnakazato@aptaregional.sp.gov.br.
}

Luiz Fernando de Orini e Paulillo

Departamento de Engenharia de Produção, UFSCar, Rod. Washington Luís, Km 235, CEP 13565-905, São Carlos, SP, Brasil, e-mail: dlfp@ @ power.dep.usfcar.br

Recebido em 05/7/2005

Aceito em 22/2/2006

Resumo

O objetivo deste artigo é verificar a formação distribuição de recursos dinâmicos de poder das empresas processadoras avícolas do estado de Santa Catarina. O desenvolvimento do sistema de contratos de integração na avicultura catarinense teve influencia de diversos fatores: características históricas (experiência com a suinocultura), regional (proximidade com a cultura da soja), participação política, ações individuais e coletivas (associações) dos atores, recursos dinâmicos de poder (constitucionais, tecnológicos, financeiros, políticos, organizacionais e jurídicos). Nesse contexto, foi possivel concluir a avicultura sulista teve trajetória de dependência (path dependence) bem distinta, o que conduziu à estruturação do sistema de contratos de forma mais eficiente do quem outras regiões do país.

Palavras-chave: avicultura, capacidade dinâmica, sistemas de contratos, Santa Catarina.

\section{Introdução}

O setor agroindustrial avícola brasileiro é um dos mais organizados do País. A coordenação executada pela indústria processadora foi eficiente para ganhar diversos mercados internacionais. A estrutura de governança de integração avícola do Estado de Santa Catarina, pautada no sistema de parcerias entre indústria, tecnólogos e produtores rurais, tornou-se o padrão de competitividade brasileira para o mercado externo.

O início da atividade avícola catarinense ocorreu de forma simultânea e diferenciada com o processo de interação organizacional, econômica e política e que resultou na formação das competências empresariais específicas para o desenvolvimento do modelo de contratos de integração. Com a estruturação do sistema de integração em contratos, as estratégias da produção e da comerciali- zação de aves do Estado de Santa Catarina foram difundidas para as outras regiões brasileiras e também para outras cadeias agroindustriais.

O objetivo do presente trabalho é apresentar uma contribuição teórica da abordagem de rede de recursos dinâmicos por meio de um estudo de caso, identificando os recursos de poder das empresas processadoras catarinenses e das associações de representação que conseguem se infiltrar no processo de orquestração de interesses daquela região. A análise empreendida ocorre sob a ótica das abordagens do institucionalismo e da organização industrial, visando determinar qual é a dinâmica da rede avícola de recursos dinâmicos no Estado de Santa Catarina e a cristalização (embeddedness) de sua dependência de rota (path dependence). Para tal, será realizado um breve

1. Este artigo é resultado da Dissertação de Mestrado intitulada "Análise comparativa dos mecanismos de governança das redes agroindustriais avícolas da Macrorregião de Ribeirão Preto - SP e de Santa Catarina “, defendida pela primeira autora no Programa da Universidade Federal de São Carlos. Esse trabalho obteve auxílio financeiro da FAPESP. 
histórico do desenvolvimento da avicultura catarinense e a caracterização das competências individuais, bem como o apontamento dos recursos obtidos pelas empresas de processamento agroindustrial. As informações que embasaram o estudo de caso foram colhidas em fontes secundárias e em entrevistas semi-estruturadas realizadas junto a alguns atores-chave da rede avícola catarinense. $\mathrm{O}$ item 2 discorre brevemente sobre o referencial teórico institucional da rede de recursos e seu potencial para analisar casos agroindustriais complexos, pautados em mecanismos de governança desenvolvidos, negociações e regimes contratuais complexos e desempenho competitivo elevado, como é o caso da agroindústria avícola catarinense. $\mathrm{O}$ item 3 explica os processos de formação e desenvolvimento dos contratos de integração e o item 4 discorre sobre outros fatores determinantes para a difusão e institucionalização do modelo de integração avícola catarinense. $\mathrm{O}$ item 5 aponta as principais características das empresas de processamento para o estabelecimento da dependência de rota naquela região avícola do Brasil para que, no item 6 , sejam feitas as conclusões do trabalho.

\section{Referencial teórico de rede de recursos dinâmicos de poder}

No capitalismo atual, a estruturação de mercados em redes de poder é mais perceptível. Primeiro, porque há a emergência de uma sociedade com base em organizações coletivas (associações de representação de interesses, sindicatos, grupos de pressão, lobbies, etc.). Segundo, porque há um crescente processo de realização de políticas setoriais ou subsetoriais. Terceiro, porque o enfoque de rede aumenta os alvos de intervenção pública e há uma crescente disputa de interesses no comando desses processos. Quarto, porque cresce a fragmentação e a descentralização do Estado, desequilibrando os limites entre o público e o privado. Quinto, porque há o fenômeno da transnacionalização das políticas públicas e, por fim, a matriz de informações assume uma relevância nunca vista anteriormente, por causa da interdependência e da complexidade dos assuntos econômicos, políticos e sociais (Kenis e Schneider, 1989, p. 6-14, citado por Paulillo, 2002).

Nos processos de concorrência, os recursos dinâmicos determinam a posição de uma empresa sobre a(s) outra(s) e também sua dependência em relação aos seus fornecedores. Assim, processos de decisão são dependentes de capturas de recursos de poder $^{2}$ por parte das empresas. Esses recursos podem ser financeiros, tecnológicos, organizacionais, políticos, jurídicos e constitucionais (Paulillo, 2000).

2. Para o artigo a palavra recurso terá o sentido de agregação dos ativos (tangíveis e não tangíveis) mais competências.
Nessa dependência de recursos estão variados entornos organizacionais. Entre eles destacam-se as cadeias agroindustriais, que se desenvolveram no Brasil sob orquestrações complexas entre empresas, agricultores, fornecedores de serviços, o Estado e suas agências públicas, associações ou grupos de representação de interesses, agentes parlamentares, lobbies, organizações não-governamentais, etc.

As redes surgiram nos variados complexos agroindustriais brasileiros porque os atores privados e públicos trataram de conquistar maior poder de negociação e, também, de influenciar os resultados econômicos e políticos. Sabe-se que a rede é o locus no qual podem ser elaboradas e administradas as políticas públicas e os processos de concorrência, porque daí se gesta qualquer governança entre atores e organizações, que são dependentes de recursos de poder (Paulillo, 2000).

Nos estudos das redes, é crescente o uso do referencial teórico do institucionalismo para dar conta do entendimento da complexidade de eventos do tipo transações econômicas, desenvolvimento de políticas públicas, dinâmica e cultural organizacional, etc. No plano do desenvolvimento das políticas públicas, o novo institucionalismo enfatiza a dependência da política em relação à sociedade, em favor de uma interdependência entre instituições políticas, econômicas e sociais relativamente autônomas (March e Olsen, 1993).

Dessa forma, os desenvolvimentos históricos das organizações estão ligados aos movimentos de path dependence, nos quais as instituições produzem dependência a partir de rotinas, sem ignorar a estratégia dos indivíduos. Eles procuram explicar porque as instituições produzem essa dependência em sua trajetória para, finalmente, assumir que o processo de criação institucional volta-se aos acordos voluntários entre os atores relevantes, que proporcionam a sobrevivência da instituição dentro de um processo de seleção competitiva.

As transações econômicas são muito bem explicadas pelo viés institucionalista da economia dos custos de transação, quando enfatiza que os atores econômicos (agindo sob incerteza, racionalidade limitada e oportunismo) decidem estrategicamente pela governança mais eficiente, pautada nas especificidades dos ativos, nas frequiências das negociações e nas administrações das assimetrias de informações (todas presentes na rede em que estes empresários atuam).

Já os conceitos embutidos na abordagem da visão baseada em recursos (VBR) de Penrose (1959) e da capacidade dinâmica (Teece et al., 1997) podem complementar análises dos mecanismos de governaça, dos mais singelos aos mais complexos. Esse mecanismo de governança proporciona as oportunidades de ações (fundamentadas em estratégias pautadas em recursos e no desenvolvimento da capacitação dinâmica) como deter- 
minantes das atuações dos agentes coletivos e individuais em rede ${ }^{3}$.

A formação dessa rede interfere na estrutura de oportunidades que se forma em torno dos processos de orquestrações de interesses e de busca de recursos de poder. Assim, a existência de uma disputa pelos "raros" recursos de poder deve afetar a dinâmica de um setor ou encadeamento agroindustrial.

Os recursos envolvidos podem "construir ou orquestrar" capacidades dinâmicas, que são o enraizamento ou cristalização (embeddedness) do processo de criação, instalação, coordenação, integração, reconfiguração ou transformação de recursos contextualizados nas firmas e/ou organizações (que geram retornos econômicos por meio das estratégias empregadas)

Entretanto, para uma organização manter sua competência frente aos processos de competitividade e de orquestração políticas, ela deve ser capaz de adaptar, integrar e reconfigurar suas habilidades financeiras, tecnológicas, organizacionais e políticas e rever seus recursos de poder, de forma a encontrar congruência com as mudanças institucionais e com mudanças no mercado (Mello, 2005).

Já Teece et al. (1992, p. 15) argumentam que as escolhas passadas é que influenciam, isto é, as firmas é que seguem as trajetórias das rotas de competência já desenvolvidas. Isso porque decidir quais caminhos seguir sob um contexto de incerteza é o problema estratégico central confrontado pela firma ou qualquer outra organização. Esta é a noção de path dependence, que reconhece a importância da trajetória histórica no comportamento futuro da organização. Em relação ao meio ambiente de seleção, o próprio processo de competição garante as mudanças nas capacidades dos competidores, pela seleção (somente o mais apto sobrevive) ou adaptação (os menos aptos tentam se reajustar às mudanças organizacionais). Portanto, a criação das capacidades dinâmicas, pelas empresas, é o valor-adicional por combinações inimitáveis de recursos raros.

\section{O desenvolvimento dos contratos de integração ou sistema de contratos na avicultura catarinense}

A avicultura comercial brasileira surgiu em São Paulo, na região de Mogi das Cruzes, nos anos 40. No final dos anos 50, observou-se uma modernização da produção, com novas granjas e novos métodos de manejo, que contavam com a atuação do Instituto Biológico de São Paulo no controle sanitário e biológico. A partir de 1960, ocorreu a importação de linhagens específicas para corte, e a avicultura paulista passou a se expandir dentro do pa-

3. Para revisão mais aprofundada do referencial teórico de rede, ver em Pinotti (2005). drão observado. Nessa mesma época, iniciava-se, ainda em condições modestas, a avicultura no oeste do Estado de Santa Catarina, organizada sob o sistema de contratos de parceria entre abatedouros e criadores, com base no modelo americano de integração e na experiência acumulada na região pela parceria na produção de suínos. $\mathrm{O}$ fato curioso é que a atividade avícola brasileira teve início no Estado de São Paulo, mas foi no Estado de Santa Catarina que a atividade teve o seu desenvolvimento mais expressivo.

A evolução da criação para os sistemas intensivos de produção (estabulação e rações) ocorreu após a Segunda Guerra Mundial, quando houve a retomada do crescimento econômico. Verificou-se, então, o deslocamento do setor dinâmico do comércio mundial dentro do segmento de carnes para o frango e, em menor grau, para o suíno. Essa transformação implicou, basicamente, numa mudança nos produtos comercializados - de carne bovina para o frango - e do eixo de exportações - do Cone Sul para os EUA. O destino das exportações se manteve no mercado europeu. Além disso, a mudança para sistemas intensivos de produção pautada em carne branca, possibilitou a auto-suficiência na Europa, que começou a proteger e estimular a indústria avícola. Após a "guerra do frango" entre os EUA e a Comunidade Econômica Européia (CEE) em 1962, um novo modus vivendi foi alcançado, envolvendo uma nova mudança no comércio mundial - cresce a importância das rações, com os EUA dominando as exportações de soja (Ries, 1978 apud Coutinho, 1993).

Nos anos 70, ocorreu um processo de reestruturação industrial, cuja dinâmica foi dada pelas empresas líderes localizadas em Santa Catarina. Com o processo de modernização com base na cultura da soja, o Paraná constituiu-se em principal área de fronteira agrícola, tornando-se importante produtor dessa oleaginosa. Isso não só acarretou alteração na base técnica da produção agrícola, com seus reflexos sobre a estrutura fundiária e aceleração do processo migratório rural-urbano, como também possibilitou a instalação de grandes empresas de capital nacional e estrangeiro no processamento dessa matériaprima. A expansão da soja, entre 1970 e 1980, se deu de forma rápida: na Região Sul, ela aumentou mais de quatro vezes em termos de área colhida e em aproximadamente seis vezes a quantidade produzida (Rizzi, 2003).

A partir da soja, se obtém uma série de produtos que se destinam à alimentação humana e animal. $\mathrm{O}$ farelo é o principal subproduto em termos de extração de proteínas, que são transformadas em proteína animal, é utilizado na ração ${ }^{4}$, combinado principalmente com o milho, atenden-

4. O milho e o farelo são componentes básicos das rações, correspondendo a aproximadamente $80 \%$ dos insumos utilizados na avicultura de corte (Miranda apud Rizzi, 2003). 
do ao setor avícola. Essas condições, aliadas às políticas públicas de incentivos à implantação de indústrias, permitiram que se combinassem diversas atividades complementares da cadeia produtiva do complexo de carnes, em especial a avicultura. O processo de integração, que inclui a produção de farelo de soja e de ração, é encontrado especialmente nas empresas líderes do setor avícola nacional.

Outros fatores da estruturação ocorreram devido à ampliação da escala de produção, como inovações tecnológicas em sua cadeia produtiva que permitiu reduzir substancialmente os custos e os preços, bem como criar variedades de produtos com maior potencial de difusão e ampliação de mercados. Deve-se ter em conta também que sua expansão é fruto do desenvolvimento do mercado interno de grande potencialidade. $\mathrm{O}$ crescimento urbano, nos anos 70 e 80, em função do forte processo de migração rural-urbano e da incorporação cada vez maior da mulher no mercado de trabalho, ampliou as bases de desenvolvimento da indústria de bens de consumo não duráveis em geral e, dentro dela, a indústria de carne de frango. As opções de produtos industrializados passaram a compor a cesta de consumo familiar, como os frangos congelados, pratos congelados e embutidos. Com o plano de estabilização econômica, o Real em 1994, ocorreu uma ampla difusão do consumo da carne de frango devido à redução substancial do preço em relação a outras carnes e à maior distribuição de renda no início desse plano econômico. As empresas catarinenses, com a coordenação no sistema de integração, estavam mais adequadas para atender a um aumento repentino na demanda de carne de frango.

A partir de meados da década de 90 , essas empresas avícolas expandiram seus limites territoriais na nova fronteira agrícola no Brasil, em direção ao centro-oeste do país. Assim, o movimento para o centro-oeste seguiu a trilha do binômio milho-soja, dispondo de microclimas adequados ao processo produtivo-tecnificado e contando com arrojados empreendedores locais e regionais com grande potencial para crescimento e para se tornar uma nova fronteira da agroindústria avícola brasileira.

O faturamento dos grupos de empresas líderes do setor cresceu em torno de três vezes durante a década de 80 , a partir da realização de grandes investimentos, na aquisição e construção de plantas, apoiados em financiamento próprio, fundos do BNDES e, no caso da Região CentroOeste, em um mix de fundos, incentivos locais e regionais. Isto levou algumas empresas a um nível de endividamento que, por um período, representou uma ameaça ao fôlego de crescimento. As empresas se diversificaram muito na década de 80 , articulando suas atividades ao longo e por meio das cadeias, bem como negociando a dinâmica diferenciada dos mercados domésticos e internacionais (Wilkinson, 1993).

O setor de carne de frango é conhecido por seu dinamismo em relação à adaptação ao ambiente competitivo, principalmente na área econômica e política. O desenvolvimento do setor avícola brasileiro teve influência das experiências oriundas da atividade de suinocultura sulista e obteve resultados expressivos, como a redução do custo de produção (o repasse de baixos preços da carne de frango no mercado interno em relação as carnes bovina e suína), melhoria na qualidade de seus produtos, inserção no mercado externo, elevação no consumo per capita brasileiro e a notoriedade do desempenho produtivo do setor em relação aos outros complexos de carne (bovino e suíno) (Pinotti, 2005).

Autores como Collier e Collier (apud Hall e Taylor, 1996; 2003) defendem que a causalidade social depende da trajetória de dependência percorrida (path dependence) e das instituições existentes. As características de cada entorno produtivo estabelecem a trajetória e moldam as instituições, portanto, apresentam dificuldades de reprodução dos mesmos resultados econômicos e sociais em lugares diferentes. As primeiras unidades produtivas instaladas no Estado de Goiás pela empresa Sadia não apresentaram os resultados esperados. As principais dificuldades encontradas foram a falta de mão-de-obra familiar, cidade com características de colônias de imigração (harmonia entre as famílias), e a identificação da sociedade com as novas empresas instaladas. No segundo momento, as empresas foram incorporando as aprendizagens organizacionais para evitar repetição das experiências mal sucedidas anteriormente e passaram a migrar adequando suas estratégias às características da região, como a elevação da escala de produção agrícola, do nível de financiamentos públicos e maior envolvimento das empresas com os problemas sociais das cidades (Pinotti, 2005).

O grau de articulação entre os diferentes elos da rede de governança agroindustrial catarinense de frango de corte é um dos mais elevados nas atividades de agropecuária nacional. Sob a coordenação das agroindústrias de abate e processamento, sobretudo por meio dos contratos estabelecidos com a base de produção rural para terminação de frangos e de joint ventures estabelecidas com grandes empresas multinacionais no desenvolvimento genético, este circuito de produção agroindustrial atingiu elevados patamares de desenvolvimento ao longo dos últimos 30 anos.

O sistema de integração funciona de forma híbrida, ou seja, são sistemas de quase-integração vertical. Eles envolvem contratos complexos e arranjos de propriedade parcial de ativos em que, via de regra, a firma "integradora" fornece as matrizes de produção (pinto de um 
dia), o arraçoamento, os medicamentos e toda a assistência técnica, enquanto o produtor "integrado" entra com a mão-de-obra, as instalações, a água, a energia elétrica, o gás e os equipamentos, num contrato de fornecimento exclusivo (Monteverde e Teece, 1982 apud Jank, 1996, p. 79). Este tipo de integração contratual produz

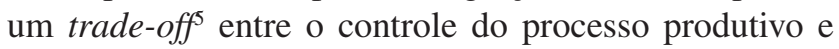
comercialização por parte da indústria e a autonomia na combinação de atividades e uso de insumos por parte do produtor. Esse sistema de integração, na nova economia institucional, é classificado como estrutura de governança de contratos formais entre as empresas processadoras e os proprietários rurais.

O debate semântico da expressão sistema de integração na avicultura existe porque alguns atores dessa agroindústria denominam, equivocadamente, de "sistema de integração vertical”. Esse termo não é apropriado em decorrência do coordenador, a indústria, não possuir o controle total dos ativos envolvidos no processo da produção da carne de frango. Portanto, neste trabalho será adotado sistema de integração ou formas contratuais para o termo usualmente chamado de integração vertical. Outro ponto importante é a relação contratual (em duplo sentido ou reciprocidade) - na forma em que os neo-institucionalistas defendem - na qual as relações são complexas e eficientes. Sendo assim, a influência das instituições não é apenas de forma hierárquica nos indivíduos e organizações, mas também os indivíduos ou organizações podem interferir nas instituições e nas relações de poder entre os atores da rede.

Os produtores rurais, quando entram nesse sistema de integração ganham escala de produção, eficiência econômica (economias de escala reais e pecuniárias, possibilidades de diversificação da produção e de diferenciação do produto) e a inserção no mercado consumidor. Em geral, essa situação representa uma sensível melhoria sócioeconômica vis-à-vis a realidade de quase (ou completa) subsistência. Para constatar essa realidade, Jank (1996, p. 114) sugere observar as "filas" de pequenos produtores desejosos de entrar no sistema de integração contratual das indústrias avícolas no Estado de Santa Catarina.

A remuneração básica do sistema contratual advém dos resultados individuais de cada granja em termos do peso, idade final dos animais, índices de conversão alimentar e a mortalidade obtida. Por exemplo, no caso da Sadia, a remuneração básica do produtor no sistema de contratos é dada por uma fórmula na qual entram os seguintes números: meta da empresa em termos de ganho de peso diário, idade do lote, peso total do lote, número de pintos de um dia enviados ao produtor e consumo total

5. Representa uma situação de escolha conflitante, isto é, quando uma ação econômica que visa à resolução de determinado problema acarreta inevitavelmente outros (Sandroni, 1994). de ração. O preço recebido pelo produtor nos sistemas contratuais possui uma pequena relação com os preços de mercado obtidos por produtores independentes. De fato, uma vez que a margem de lucro é prefixada, o sistema contratual acabou possibilitando ao produtor um retorno pequeno, porém sempre positivo em decorrência do menor risco (Jank, 1996).

O problema desse sistema de governança contratual para os granjeiros é quando a empresa contratante possui dificuldades para o cumprimento de contratos, como ocorreu em 2003 com a empresa Chapecó. Durante a crise financeira da empresa, os produtores rurais ficaram sem receber pela produção durante muitos meses e tinham dificuldades de negociar com outras empresas em decorrência do contrato possuir exclusividade de vendas para a Chapecó. Mesmo assim, a estrutura de governança predominante na avicultura de corte nacional é o contrato formal entre indústrias e produtores rurais (Pinotti, 2005).

Notou-se que esse processo de integração contratual, no Estado de Santa Catarina, proporcionou às indústrias coordenar a cadeia produtiva, desde a preparação das matrizes, fabricação de ração, criação de aves, abate, processamento, até a distribuição ao varejo. Via de regra, o produtor de frangos de corte especializa-se unicamente na engorda das aves, não tendo que se preocupar com a criação dos pintos, a produção de rações ou com a comercialização da produção. Dessa forma, o produtor integrado possui insignificante poder de negociação da sua produção, mesmo quando não está satisfeito com o contrato imposto pela indústria processadora (Pinotti, 2005).

\section{Outros fatores para a difusão e institu- cionalização do modelo de integração}

Wilkinson (1993) considera que os fatores para a rápida modernização do setor de aves decorrem da convergência de um conjunto de fatores - tradição agrícola, disponibilidade de recursos públicos, vigor dos empresários da agroindústria, forte participação do setor público de pesquisa e assistência técnica, difusão de novas tecnologias (genética e nutrição), novos hábitos de consumo, planejamento, logística e qualidade.

No modelo avícola catarinense, as variáveis acima são relevantes e já foram apontadas por outros trabalhos, mas o modo pelo qual algumas empresas detiveram os recursos políticos (via representação coletiva, status público, poder executivo, lobbying e tráfico de influência) e financeiros (bancos de fomento, incentivo fiscal, subsídio, aumento de exportações, ganhos de produtividade agrícola e/ou industrial) não foi analisado até o momento por pesquisadores e/ou estudos do setor. O reconhecimento da importância dessa disputa dos recursos dinâmicos de poder para obtenção de vantagens competitivas sustentáveis das empresas é uma das justi- 
ficativas do presente trabalho. A disputa ocorre por meio da orquestração de interesses dos atores na rede avícola (Pinotti, 2005).

A associação entre capacidade dinâmica (Teece et al., 1992; 1997) dentro do conceito de perspectiva baseada em recursos (Penrose, 1959) é o aporte teórico de recursos de poder (do neo-institucionalismo - policy network), uma possibilidade de compreender o mecanismo de governança específico para a região avícola catarinense. Um mecanismo de governança diferenciado pode ser visto como uma oportunidade de ação dos atores coletivos $\left(\mathrm{UBA}^{6} \mathrm{e}\right.$ $\mathrm{ABEF}^{7}$ ) e individuais (empresas individuais, agrícolas, etc.) para interferir na estrutura de negociações que se forma em um setor produtivo. Nesse contexto, a busca por recursos dinâmicos de poder, por meio da representação e da distribuição dos interesses dos atores, tornou-se fundamental para a dinâmica da competitividade do setor, pois proporciona a realimentação do poder por meio da distribuição dos recursos (Pinotti, 2005).

As associações de interesses empresariais da avicultura possuem a função de representar as demandas industriais, assim como ocorre na maior parte do setor agroindustrial brasileiro. No plano nacional, os abatedouros avícolas estão representados, basicamente, por duas entidades: a ABEF e a UBA. Embora haja alguma sobreposição entre essas entidades, elas se distinguem por dois motivos. Primeiro, a representação da $\mathrm{ABEF}$ é mais restrita, atrelada ao grupo de empresas exportadoras, voltando-se à representação de negociações externas, distribuição e comercialização internacional do frango e seus embutidos. Desse modo, sua representação restringe-se ao grupo de estratégias bem definidas, empresas líderes de mercado que são capazes de explorar esse nicho de mercado ${ }^{8}$. Segundo, a UBA tem como ênfase o montante da cadeia produtiva, seja no material genético utilizado na produção de pintos, seja na relação com granjas, seja no acompanhamento das safras dos insumos básicos (milho e soja) e o mercado de rações de um modo geral. Há, portanto, aglutinação entre a UBA e associações de interesse do sistema agroindustrial de milho (Associação Brasileira das Indústrias do Milho - Abimilho), ração (Sindicato Nacional da Indústria da Alimentação Animal - Sindirações), setores

6. União Brasileira de Avicultura.

7. Associação Brasileira dos produtores e Exportadores de Frangos.

8. O mercado consumidor externo possui exigências elou preferências específicas na área sanitária e cultural (religiosos, preferências de corte, idade e outros). Um exemplo curioso são os produtos para os países de origem árabe que possuem critérios de processamento para seus alimentos, dessa forma, o abate dos animais precisa seguir as normas estabelecidas pelos compradores (o ato de morte dos animais tem de ser voltado para a cidade de Meca). produtivos (suínos), fabricantes de equipamentos e outras entidades que representam o agronegócio brasileiro. Portanto, a disputa pelos principais objetivos dessas associações distintas conflui-se na UBA, em decorrência da maior diversificação de interesses dos associados.

A organização produtiva da avicultura encontra-se num estágio mais avançado em comparação com outros setores de carnes. Nos últimos anos, os atores da rede avícola concentraram seus esforços no controle sanitário em todos os segmentos da cadeia produtiva. Dessa forma, a UBA teve atuação marcante nas ações na área sanitária, como, em 1994, participação ativa nas decisões políticas do setor, sendo que a principal foi a participação na criação do PNSA (Programa Nacional de Sanidade Avícola) em conjunto com o Ministério da Agricultura e Abastecimento e da Reforma Agrária (MAARA), Secretaria de Defesa Agropecuária (SDA) e Departamento de Defesa Animal (DDA). O PNSA executa as normas de defesa e inspeção sanitária animal que devem obedecer à legislação em vigor e demais normas a serem determinadas pelo MAARA. O objetivo desse programa é aumentar a disponibilidade, nos mercados interno e externo, de produtos avícolas de qualidade, mediante o incentivo às empresas, por meio dos termos de parceria, destacando-se, nestes, o controle oficial, a produtividade e as exportações com controle sanitário pelo setor privado. As áreas das atividades avícolas a serem abrangidas são (UBA, 2004):

- Parque criatório (avoseiros e matrizeiros);

- Incubatórios;

- Terminadores;

- Abatedouros e frigoríficos;

- Trânsito nacional e internacional;

- Rede laboratorial (pública e privada/credenciada); e

- Controle de insumos e imunobiológicos.

Em relação à estrutura organizacional do PNSA, existe a participação de vários órgãos públicos e privados, como (UBA, 2004):

- Órgãos públicos: Ministério da Agricultura do Abastecimento e da Reforma Agrária (MAARA), Secretaria de Defesa Agropecuária (SDA), Departamento de Inspeção de Produtos de Origem Animal (DIPOA), Departamento de Defesa Animal (DDA), Secretaria Estadual de Pesquisa, Embrapa- avícola, Universidades e Institutos de Pesquisa; e

- Órgãos da iniciativa privada e associações que se reúnem no Programa Nacional Comitê Consultivo Nacional de Sanidade: compostos por Laboratórios, UBA e seus órgãos executores, Sindicato de Indústria de Carnes e derivados (SINDICARNES), Sindicato de Defesa Animal (SINDAM), dentre outros. 
Os recursos financeiros utilizados pelo PNSA são procedentes do fundo do Tesouro Nacional e do Projeto de Doença dos Animais e por meio do convênio com o Banco Internacional de Reconstrução e Desenvolvimento (BIRD). O objetivo desse programa é conseguir concretizar os interesses para exportação das grandes indústrias do setor, em decorrência das exigências do mercado internacional serem rigorosas em relação às condições sanitárias das carnes importadas. Tanto o objetivo do programa quanto sua estrutura organizacional são indicações feitas pela UBA, que por sua vez é o representante oficial das maiores empresas processadoras e exportadoras do setor.

A UBA tem um relacionamento muito próximo na arena política, principalmente, em relação ao governo federal. Um exemplo físico é que a entidade possui um escritório em Brasília, para acompanhamento de processos políticos do setor, e outro em São Paulo, para as atividades produtivas e econômicas. A concessão das dependências do Palácio Itamaraty para a realização do $18^{\circ}$ Congresso Brasileiro de Avicultura da UBA, em outubro de 2003, pelo Ministério das Relações Exteriores, é outro exemplo. Esse evento também teve o apoio do Ministério do Desenvolvimento, Indústria e Comércio Exterior, em decorrência do ministro ser um dos principais acionistas e herdeiro da Sadia, portanto, um forte representante do setor avícola no cenário político nacional. Desse evento resultou o compromisso formal da UBA, ABEF e MAARA por meio da assinatura do convênio de cooperação técnica para intensificação do programa nacional de controle e melhoria da qualidade do frango que visa atender ao cumprimento de barreiras não tarifárias para a exportação das empresas (Pinotti, 2005).

Segundo declarações do diretor da UBA, a entidade possui legitimidade de representação junto ao setor produtivo e ao poder executivo federal. A acessibilidade às formulações e às implantações de políticas públicas do setor não estão condicionadas à gestão político partidária de um mandato presidencial, mas sim aos interesses das grandes empresas processadoras do setor avícola nacional. Portanto, o status público para negociação das políticas setoriais na avicultura foi concedido para a UBA. Percebe-se que as ações realizadas pela UBA sempre objetivam os interesses das empresas líderes do setor que possuem origem no Estado de Santa Catarina. Nos serviços prestados pela entidade aos seus associados estão o acompanhamento de processo, requerimentos de qualquer natureza junto aos governos Estadual e Federal, ocorrência de reuniões, audiências com o ministro e até mesmo com o Presidente da República para ouvir os interesses da UBA e empresários do setor. Fica evidente, no discurso do seu presidente, Zoe Silveira D'Avila9:

9. O atual presidente da UBA, Zoe Silveira D'Avila, pertence à família fundadora da empresa Sadia.
"É imperativo, para o sucesso de um determinado pleito, que pelo menos um secretário da fazenda estadual apresente interesse pelo mesmo. A experiência passada revela que é muito limitado o que a UBA pode realizar para influenciar as decisões tomadas pelos secretários de fazenda estaduais, quando reunidos no Confaz ${ }^{10}$." (UBA, 2004).

Dessa forma, a UBA se isenta de qualquer esforço de defender os interesses de rede avícola que não seja prioridade em seus Estados de origem. A UBA consegue obter recursos políticos e constitucionais para os atores privados da rede avícola do Estado de Santa Catarina, principalmente, pelo motivo de seu presidente ser membro da família fundadora da Sadia. A combinação de recursos é importante para obter resultados positivos para o interesse de uma rede de poder específica, como é a catarinense. Historicamente, a composição da diretoria dessa entidade sempre teve a presença das grandes empresas industriais catarinenses (Sadia, Perdigão, Seara, Aurora) ${ }^{11}$.

Em relação ao poder de negociação, a $\mathrm{ABEF}$ tem maior destaque porque as empresas associadas partilham de objetivos em comum que estabelecem regras de conduta interna que levam a uma mesma lógica de ação. Assim, proporcionam uma forma de atuação mais homogênea entre os atores do grupo, em comparação à UBA, facilitando o consenso sobre a decisão que deve ser adotada. Entre as principais ações dessa entidade estão: 1) abertura de novos mercados externos, sendo que a comercialização já é feita com mais de 100 países; 2) restituição de 5,37\% dos tributos (Programa de Integração Social - PIS e Contribuição para Financiamento da Seguridade Social - COFINS) incidentes no processo produtivo da carne de frango exportada, melhorando os custos para competitividade do produto no mercado externo; 3) aglutinação de mais associados para aumento da base exportadora; e 4) obtenção de um porta-voz direto dos objetivos dessa entidade com o Ministro de Desenvolvimento, Indústria e Comércio (um dos herdeiros da Sadia) (Pinotti, 2005). No Quadro 1, foram elencados as funções na rede e os principais recursos das empresas processadoras catarinense e as associações de interesse (UBA e ABEF).

A UBA e a ABEF possuem sinergia de atuação em decorrência de ambas defenderem os interesses das empresas líderes da avicultura brasileira. Assim, o nível de penetração das associações de representação de interesse das empresas industriais na área política torna-se decisivo para as empresas atuarem em seus mercados.

A orquestração política sempre esteve presente nas empresas avícolas catarinenses, tanto que, nas cidades

10. O CONFAZ é o Conselho Nacional de Política Fazendária. 11. Para maiores detalhes desse assunto ver Pinotti (2005). 
Quadro 1. Recursos dinâmicos de poder dos principais atores avícolas presentes na rede de poder catarinense.

\begin{tabular}{cl}
\hline \multicolumn{1}{c}{ Ator } & \multicolumn{1}{c}{ Indústrias processadoras: Sadia, Perdigão e Chapecó } \\
\hline Função na rede & $\rightarrow$ responsável pela coordenação da produção, comercialização e logística de carne de frango com eleva- \\
& do valor agregado no mercado interno e externo; e \\
& $\rightarrow$ influência nas instituições políticas, econômicas e sociais. \\
\hline Principais recursos & $\rightarrow$ recursos organizacionais elevados: infra-estrutura institucional, integração para trás e para frente, con- \\
& sórcios, proximidade com os fornecedores (granjeiros) e/ou consumidores, utilização de marca, controle \\
& do mercado externo, diferenciação do produto, elaboração de contratos de fornecimentos, formação de \\
& pool de comercialização; \\
& $\rightarrow$ recurso político elevado: benefícios privados obtidos pela utilização de influências do poder político na \\
& esfera executiva e de suas agências públicas; \\
& $\rightarrow$ recurso financeiro elevado: incentivo fiscal modificado ou concedido, subsídio modificado ou conce- \\
& dido, crescimento da produção, ganhos de produtividade agrícola e/ou industrial, redução nos custos de \\
& produção e/ou transação, aumento e/ou controle das exportações; e \\
& $\rightarrow$ recurso tecnológico: emprego de tecnologia na produção (PIPA), certificação (Sadia para exportação \\
& a Europa). \\
\hline Ator & $\rightarrow$ representação, na esfera política, das indústrias avícolas de SC no setor. \\
\hline Função na rede & $\rightarrow$ recursos políticos: essas organizações possuem legitimidade, reputação e status público, o que lhes \\
Principais recursos & confere poder de representação considerável junto aos órgãos estatais e consumidores internacionais. \\
& Mas, efetivamente, essas entidades representam estritamente os interesses das grandes indústrias de Santa \\
& Catarina, em decorrência da diretoria das associações ser dessas empresas. Ex: criação do PNSA e a rela- \\
&
\end{tabular}

Fonte: elaboração da autora.

de origem das grandes empresas processadoras, confundem-se as empresas e as instituições públicas locais. O cenário político, econômico e social das cidades catarinenses, onde estão instaladas as empresas processadoras, possui identificação cultural com as atividades produtivas avícolas. Os cargos políticos dos municípios e depois do Estado tiveram ligações com as atividades empresariais desde a instalação das primeiras unidades produtivas na região. Essa experiência de se inserir na política para obter resultados positivos nos empreendimentos privados foi expandida para as associações de interesses (UBA e ABEF) em outras regiões produtivas (São Paulo e Centro-Oeste) (Pinotti, 2005).

\section{As características históricas das empresas processadoras do estado de Santa Catarina}

O início da atividade avícola catarinense foi marcado pelas relações formais em decorrência da distância do mercado consumidor, em especial do Estado de São Paulo. Outra característica regional foi a formação étnica de colônias de imigrantes oriundos da $1^{\mathrm{a}}$ e da $2^{\mathrm{a}}$ Guerra Mundial que possibilitou um padrão fundiário caracterizado por pequenas propriedades de exploração familiar. $\mathrm{O}$ conjunto de fatores iniciais que influenciaram o desenvolvimento das competências dos atores na avicultura catarinense ocorreu em cidades incipientes (política e economicamente) na região. As atividades avícolas entre atores produtivos não haviam estabelecido qualquer nível de confiança (trust) e o mercado consumidor local era quase inexistente. Nas palavras do fundador da empresa Sadia, Attilio Fontana, pode-se perceber a importância que as relações formais tiveram no início das atividades avícolas em Santa Catarina (Fontana, 1980, p. 134):

"Em 1944, já desenvolvíamos o sistema de parceria (depois de contratos de integração) na suinocultura, a empresa fornecia as matrizes em meia gestação e o lavrador aceitava a implantação de novas técnicas de criação (instalações adequadas e toda higiene possível) para as matrizes fornecidas e o propósito de melhorar também sua própria criação."

A importância da experiência do sistema de parceria da suinocultura, entre o produtor rural e a empresas de abate, foi, posteriormente, implantada na produção de carne de frango. O sistema de integração introduzido pelas empresas líderes foi o elo entre a produção rural de frangos (atividade rural) e a atividade industrial, pelo fornecimento programado de matéria-prima para as firmas processadoras $^{12}$. Desde o início da atividade agrícola, os proprietários rurais reconheciam e apoiavam as decisões

12. As firmas processadoras de produtos agropecuários geralmente apresentam grandes dificuldades no fornecimento de matéria-prima que são perecíveis e sofrem influências edafoclimáticas (ciência dos solos), temperatura, umidade e sanitários. Os principais problemas apresentados são em relação à freqüência de fornecimento, volume, padrão, períodos de produção e outros. 
estratégicas das empresas frigoríficas, que, posteriormente, desenvolveram o modelo atual de contratos de comercialização da produção.

Mantzavinos, et al. (2001, p. 16) citam a importância da rota de dependência (path dependence) no processo de mudança social que pode ser resumido começando na percepção cognitiva (aprendizagem individual num determinado espaço e tempo), passando pelo nível institucional e obtendo resultado no nível econômico. Portanto, para este artigo, será adotado que a trajetória de dependência foi necessária para o processo de mudança social por meio da realidade, em que crenças são responsáveis pela formação das instituições (contratos formais), que, por sua vez, formulam políticas específicas (pela legitimação das associações de interesses) para conduzir resultados e consequiências que alteram a realidade econômica (empresas líderes).

As exportações na avicultura catarinense acompanharam a dinâmica da modernização da agricultura e modificaram sua base de produção, passando de uma atividade do tipo colonial para a industrialização da produção. Em conseqüência dessa mudança, ocorreu o surgimento de modernos frigoríficos abatedouros de aves catarinenses, que foram viabilizados pela política agrícola - vinculada fortemente às condições de liquidez financeira internacional - mais especificamente pela política de crédito subsidiando a instalação de frigoríficos e a comercialização e a instalação de aviários fornecedores de matériasprimas via produtor integrado. Assim, o processamento industrial avícola passou a ser o principal segmento da indústria de carnes, e surgiram grandes empresas que desenvolveram um esquema contratual na criação das aves junto aos produtores rurais.

A primeira parte do processo cognitivo das empresas líderes do setor avícola brasileiro foi a percepção da importância das relações comerciais serem formalizadas por meio de contratos com os produtores rurais (vale ressaltar que as propriedades rurais são predominantemente de pequeno porte em decorrência da recente colonização de imigrantes italianos), desde o início da atividade industrial no Estado de Santa Catarina. A segunda fase ocorreu com a institucionalização do sistema de integração da produção no setor avícola nacional. E a terceira fase é representada pelos resultados econômicos das grandes empresas da rede catarinense como líderes de mercado interno, atingindo o mercado externo e se posicionando entre as principais empresas na área agroindustrial nacional. Na Figura 1, pode-se observar a evolução das etapas que influenciaram na formação da situação atual das empresas líderes de frango do setor avícola.

O pioneirismo das grandes empresas líderes em atender às exigências do consumidor internacional se refletiu na busca por certificação de qualidade do produto e da produção, normas sanitárias, fortalecimento da marca e

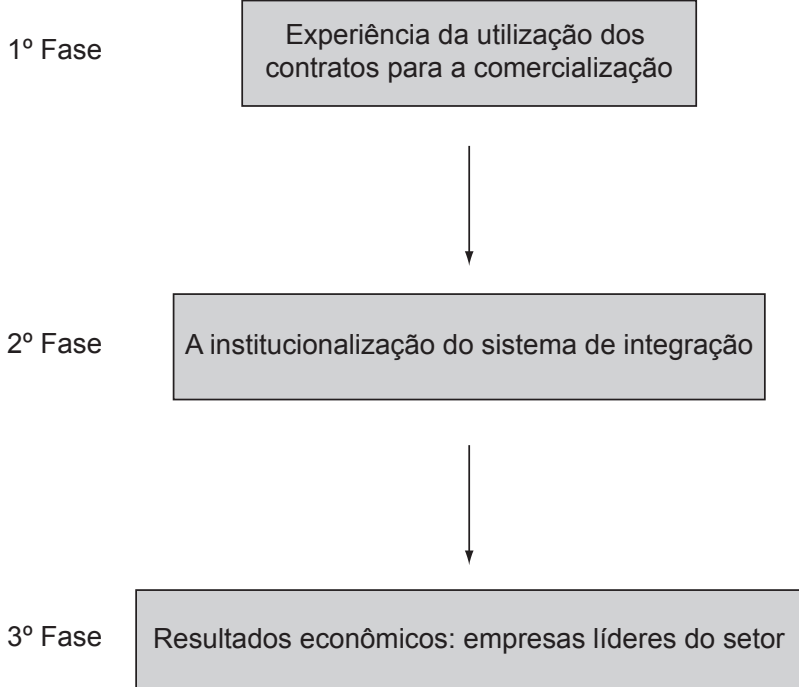

Figura 1. Fases da institucionalização da rede de empresas avícolas do Estado de Santa Catarina. Fonte: elaboração da autora.

investimento para o lançamento de novos produtos com maior valor agregado. $\mathrm{O}$ mercado consumidor das grandes empresas avícolas de Santa Catarina está caracterizado principalmente pela segmentação de mercado, com tendências qualitativas de consumo. Podem-se distinguir, desta forma, consumidores desejosos de produtos mais saudáveis, com menor nível de gordura; consumidores que valorizam a conveniência no preparo; consumidores que valorizam características organolépticas (sabor, maciez, suculência, etc.). Em suma, os consumidores desses produtos são aqueles que não decidem as suas compras pelo preço, mas sim pelos benefícios que o produto pode oferecer. Esses produtos proporcionam margens de lucro mais elevadas em relação aos produtos commodities para as empresas produtoras, pois necessitam de maiores investimentos, principalmente, em $\mathrm{P} \& \mathrm{D}$, pesquisa de mercado e fortalecimento da marca.

A dinâmica da sociedade, as relações humanas e as novas tecnologias são fatores que determinam a competitividade das firmas na rede avícola brasileira. Segundo os entrevistados, a competitividade das firmas não está apenas baseada na obtenção de menores custos de produção, mas principalmente em lançamentos de novos produtos com elevado valor agregado para obtenção de maior rentabilidade econômica para as empresas. Há necessidade de fortalecimento da marca, investimentos em $\mathrm{P} \& \mathrm{D}$, disputa por novos mercados, aporte financeiro e, principalmente, disputa por recursos de poder político (associações e financiamentos públicos) para manter e/ou alcançar níveis de competitividade. 
A experiência acumulada das empresas, o apoio político local, as disponibilidades de recursos financeiros e organizacionais privilegiaram a construção ou mesmo a reprodução do sistema de integração sulista para a produção avícola de carne de frango, situação essa que proporcionou condições de formação de uma rede de recursos dinâmicos de poder em novas regiões avícolas similares à catarinense.

\section{Conclusão}

O desenvolvimento de competências, por meio das características históricas e trajetória de dependência - path dependence -, dos gestores das empresas processadoras de Santa Catarina conduziu às estratégias operacionais mais adequadas para obtenção de resultados competitivos no setor avícola nacional. A estruturação da produção avícola catarinense ocorreu por meio da institucionalização de contratos de integração, com a influência das especificidades locais da região. Os ambientes cultural (propriedades rurais pequenas e colônias de imigrantes), histórico (experiência com a suinocultura e contratos de comercialização), econômico (acesso a financiamentos públicos) e político (associações e políticas públicas) proporcionaram condições para resultados eficientes do ponto de vista organizacional, com a implantação de sistema de integração de produção avícola no Estado de Santa Catarina.

O processo histórico de evolução dos atores industriais catarinenses, associado ao ambiente econômico e social, conduziu à eficiência do modelo adotado de estratégia empresarial. Essa situação acarretou maior poder de barganha empresarial processadora na disputa pela obtenção de recursos dinâmicos de poder. $\mathrm{O}$ resultado eficiente alcançado pelas empresas integradoras, como agentes do processo de integração, demonstrou como a disputa por recursos de poder ocorre de forma desigual entre os atores dessa rede. As significativas obtenções de recursos dinâmicos de poder das empresas e associações de interesses ratificaram a competitividade avícola local no setor agroindustrial nacional.

\section{Referências Bibliográficas}

COUTINHO, L. FERRAZ, J. C. (coord.) Estudo da competitividade da indústria brasileira. Campinas: $\mathrm{IE} /$ UNICAMP - IEI/UFRJ - FDC - FUNCEX, 1993.

FONTANA, A. História da minha vida. Petrópolis: Vozes, 1980, $278 \mathrm{p}$.

HALL, P. A.; TAYLOR, R. C. Political science and the three new institutionalism. Oxford: Blackwell Publishers. Political Studies, n. XLIV, p. 936-957, 1996.

As três versões do neo-institucionalismo. Lua

Nova, n. 58, p. 193-223, 2003.

JANK, M. S. Competitividade do agribusiness brasileiro: discussão teórica e evidências no sistema de carnes. 1996. 195p. Tese (Doutorado) - São Paulo, FEA-Universidade de São Paulo, 1996.

MANTZAVINOS, C.; NORTH, D.; SHARIQ, S.; Lerning, change and economic performance. $5^{\text {th }}$ Conference of the international society for new institutional economics, Berkeley-CA, 19 p., July, 2001. (www.isnie.org).

MARCH, J.; OLSEN, J. El Nuevo institucionalismo: factores organizativos de la vivencia política. Zona Abierta, n. 63/64, p. 1-44, Madrid, 1993.

MELLO, F. O. T.; PAULILLO, L. F. Recursos de poder e capacidade dinâmica de aprendizado dos atores sucroalcooleiros paulistas pós-desregulamentação estatal. Informações econômicas, SP, v. 35, n. 6, p. 17-29. Jun. 2005.
PAULILLO, L. F. Redes de poder \& territórios produtivos: indústria, citricultura e políticas públicas no Brasil do Século XX. São Carlos: RIMA/EDUFSCAR, 2000. 196 p.

. Análise Organizacional em Redes de Recursos de Poder: Contribuições para os Estudos da Concorrência, das Decisões Estratégicas e das Políticas Públicas. In: FUSCO, L. et al. Temas abrangentes em Engenharia de Produção. São Paulo: Unip, 2002.

PENROSE, E. The theory of the growth of the firm. Oxford: Basil Blackwell. England, 1959.

PINOTTI, R. N. Análise comparativa dos mecanismos de governança das redes agroindustriais avícolas na Macrorregião de Ribeirão Preto-SP e de Santa Catarina: São Carlos - SP, Universidade Federal de São Carlos, 2005. Dissertação (Mestrado em engenharia de Produção) - Centro de Ciências Exatas e Tecnologia, 176 p.

RIZZI, A. T. Mudanças Tecnológicas e Reestruturação da Indústria de Frangos no Brasil. Texto $\mathrm{n}^{\circ}$ 08/98. www.ecomomia.ufpr.br/departamento/docente/aldair. htm, Acesso em: 20 dezembro 2003.

SANDRONI, P. Novo dicionário de economia. 8. ed. São Paulo: Best Seller, 1994. 375p.

TEECE, D. J.; PISANO, G.; SHUEN, A. Dynamic capabilities and strategic management. Berkeley: University of 
California. Consortium, Competitiveness and Cooperations Working Paper, 1992.

Dynamic capabilities and strategic management, Strategic Management Journal, v. 18, n. 7, p. 509-533, 1997.
UNIÃO BRASILEIRA DE AVICULTURA (UBA), www. uba.com.br, 2004.

WILKINSON, J. Competitividade na indústria de abate e preparação de carnes. In: Estudo da competitividade da indústria brasileira. COUTINHO, L.; FERRAZ, J.C. (coord.). Campinas, 1993. 74p.

\title{
STRUCTURING OF THE DYNAMIC POWER RESOURCES OF POULTRY FARMING AND PROCESSING COMPANIES IN SANTA CATARINA, BRAZIL
}

\begin{abstract}
This article discusses the formation and distribution of dynamic power resources in the poultry processing companies of the state Santa Catarina, Brazil. The development of the integration contract system in Santa Catarina's poultry processing industry was influenced by various factors: historical characteristics (experience with pig breeding), regional characteristics (proximity to soybean farming), political participation, individual and collective actions of the actors (associations), and dynamic power resources (constitutional, technological, financial, legal, political and organizational). In this context, it was concluded that the poultry farming and processing industry in the state of Santa Catarina followed a very distinct path of dependence, which led to the structuring of a more efficient contract system than that of other regions in the country.
\end{abstract}

Keywords: poultry farming, dynamic capacity, contract systems, Santa Catarina. 
